\title{
Autonomia, cooperativismo e autogestão em Freinet: fundamentos de uma pedagogia solidária internacional
}

\author{
Antonio Takao Kanamaru'
}

\section{Resumo}

A moderna educação pública, a partir de fins do século XX, passou a sofrer novas influências de políticas hegemônicas de vieses tecnocrático, mercadológico e financeiro. Diante desse quadro, um de seus principais fundamentos, a autonomia pedagógica, encontrase sob pressão e condicionamento no mundo. Assim, defendemos que o estudo da autonomia na educação moderna pode auxiliar a esclarecer criticamente as condições e seu desenvolvimento na história. Nessa perspectiva, uma das reconhecidas obras pedagógicas reside na chamada Pedagogia do trabalho ou escola moderna, de Célestin Freinet (1896-1966), a qual procuramos analisar a partir de revisão da literatura. Neste trabalho, portanto, enfocamos seus meios e fundamentos teórico-metodológicos como a livre expressão, o livre trabalho, a livre cooperação, as técnicas de trabalho, a livre pesquisa, a comunicação interescolar. Na análise, observamos a presença teórica de um quadro marxiano heterodoxo implícito na metodologia freinetiana, particularmente relacionada à teoria das relações materiais de produção, à teoria da alienação e à doutrina internacionalista. Tais fundamentos, somados à originalidade de Freinet, permitiram a criação de meios técnicos e a cooperação internacional, que subjazem à autonomia radical de sua pedagogia. Como resultados, observamos e descrevemos fundamentos pouco analisados em Freinet, devido ao caráter embrionário em seu tempo e espaço: o cooperativismo internacional e a autogestão da escola moderna, os quais revelam a relevância e atualidade do autor para o resgate e o desenvolvimento da autonomia pedagógica, bem como a ampliação da dimensão da obra freinetiana como uma pedagogia solidária internacional, frente ao difícil contexto histórico presente.

\section{Palavras-chave}

Autonomia pedagógica - Cooperativismo - Autogestão escolar Pedagogia solidária.

I- Universidade de São Paulo, São 


\section{Autonomy, cooperativeness and self-management in Freinet: foundations of an international solidarity pedagogy}

Antonio Takao Kanamaru'

\begin{abstract}
Since the late twentieth century, modern public education has come under new influences of hegemonic policies with technocratic, marketing and financial biases. Given this scenario, one of its main foundations, pedagogical autonomy, is under pressure and conditioning in the world. Thus, I argue that the study of autonomy in modern education may help critically clarify the conditions and its development in history. From this perspective, one of the recognized pedagogical works is the so-called pedagogy of work or modern school, by Célestin Freinet (1896-1966), which I sought to analyze through literature review. Therefore, in this study I focus on its means and theoretical and methodological foundations such as free speech, free work, free cooperation, work techniques, free inquiry, interschool communication. In the analysis, I have observed the presence of a heterodox Marxist theoretical framework implicit in Freinet's methodology, particularly related to the theory of the material relations of production, the theory of alienation and the internationalist doctrine. Such foundations, coupled with the originality of Freinet, enabled the creation of technical means and international cooperation, which underlie the radical autonomy of his pedagogy. As for findings, I observe and describe foundations which have been little analyzed in Freinet, given their embryonic nature in his time and space: the international cooperativeness and self-management of the modern school. Such foundations reveal not only the relevance and timeliness of the author to the rescue and development of pedagogical autonomy but also the expansion of the size of Freinet's work as an international solidarity pedagogy in the difficult current historical context.
\end{abstract}

\section{Keywords}

Pedagogical autonomy - Cooperativeness - School self-management - Solidarity pedagogy.
I- Universidade de São Paulo, São Paulo, SP, Brazil.

Contact:kanamaru@usp.br 


\section{Introdução}

Na extensa obra do francês Célestin Freinet ${ }^{1}$, observamos, a partir da revisão da literatura, um aspecto pouco abordado em sua teoria e práxis pedagógicas baseadas em métodos ativos: a solidariedade radical em seus meios e fins. Solidária devido ao compromisso ético e socialmente transformador assumido em sua pedagogia popular. Radical em sentido análogo ao levantado por Paulo Freire, no clássico Pedagogia do oprimido (2005, p. 26), quanto à etimologia do próprio termo, relacionado à ideia de raiz, segundo o qual:

[...] a radicalização (grifo nosso) é crítica, por isto libertadora. Libertadora porque, implicando o enraizamento (grifo nosso) que os homens fazem na opção que fizeram, os engaja cada vez mais no esforço de transformação da realidade concreta, objetiva.

Trata-se, portanto, da solidariedade radical, da responsabilidade enraizada em sua missão, objetivos e métodos.

Essa dimensão pouco estudada na obra de Freinet pode ser observada em aspectos já analisados e amplamente reconhecidos na literatura, como aqueles relacionados às centralidades dos conceitos de livre trabalho, bem como de livre expressão, que, junto com a livre cooperação, a livre pesquisa e as respectivas técnicas (técnicas de vida), que a notabilizaram, como a impressão gráfica, o correio interescolar, o diário coletivo (livro de vida), o jornal escolar, fichas e fichário escolares, os audiovisuais (documentário cinematográfico, rádio-gravador) e a revisão do layout do interior arquitetônico e mobiliário escolares, constituem, em seu conjunto, os meios e fins da pedagogia freinetiana. Fundamentalmente, seus pressupostos conceituais e condições

1-Dedicado ao freinetiano Profofessor Titular José de Arruda Penteado (Departamentp de Educação - IA/UNESP), in memoriam. técnicas têm por objetivo conduzir educandos didaticamente ao trabalho coletivo e criador.

Mas, a nosso ver, a obra freinetiana não se limitou à celula mater didática da relação educador-educando. Compreendemos que Freinet interveio também nas próprias relações entre educadores, ao estender coerentemente a cooperação ${ }^{2}$ e a autogestão escolar a essa relação de trabalho, conforme o sétimo princípio da Carta da Escola Moderna, que descreve que:

Educadores do ICEM são os únicos responsáveis pela direção e esforços de cooperação. [...] Estamos interessados profundamente na vida da nossa cooperativa, porque é a nossa casa, nosso quintal que devemos alimentar nossos fundos, o nosso esforço, nossos pensamentos e estamos prontos para se defender contra qualquer pessoa que iria prejudicar os nossos interesses. (ICEM, 1968).

Junto com o décimo princípio, Freinet e colaboradores consideraram que o objetivo do movimento cooperativo da Escola Moderna corresponde ao ato de "[...] desenvolver o trabalho em fraternidades e para o destino de auxiliar profundamente e de forma eficaz todas as obras de paz". (ICEM, 1968).

Tal aspecto é comumente descrito na literatura, mas a análise e a discussão crítica a respeito do caráter dessa relação a qual definimos como solidária é incipiente. Isso porque suas reflexões nesse campo tornaram-se mais efetivas com as crises estruturais da segunda metade do século XX (SINGER, 2002), nas quais o debate entre concorrência e solidariedade começaram a se aprofundar e a se estender para áreas além da economia, alcançando também a pedagogia (SINGER, 2009; GADOTTI, 2009).

Com o desenvolvimento da livre cooperação entre educandos e, portanto,

2- Para Marx (1988, p. 246), "a forma de trabalho em que muitos trabalham planejadamente lado a lado e conjuntamente, no mesmo processo de produção ou em processos de produção diferentes, mas conexos, chama-se cooperação". 
também entre educadores sob autogestão escolar, entendemos a coerência da solidariedade existente na pedagogia freinetiana tanto em suas relações didáticas quanto em seu projeto político-pedagógico em sociedade.

Nesse ponto, aventamos como hipótese o cooperativismo e a autogestão como a contribuição original na obra de Freinet, caracterizando-a em um aspecto renovado: a de uma pedagogia solidária de caráter internacional. Esse caráter é frisado no décimo princípio presente na Carta da Escola Moderna, na qual se estabelece que a pedagogia Freinet é "inerentemente internacional".

Procuramos evidenciar também outro aspecto pouco abordado na obra de Freinet, mas que a fundamenta implicitamente em termos teórico-metodológicos e praxiológicos: a presença de uma interpretação marxista original, de características heterodoxas, particularmente sobre a teoria da alienação do sujeito produtor, a teoria das relações materiais de produção, que fundamenta a noção capital das condições objetivas das relações sociais históricas, e, finalmente, a doutrina internacionalista de Marx.

0 marxismo na obra de Freinet foi analisado por Élise Freinet (1979), que manteve vivo o movimento da Escola Moderna após o falecimento de Freinet. Na obra $O$ Itinerário de Célestin Freinet, Élise afirma:

[...] Fora de seu domínio pedagógico, Freinet já tem uma ampla cultura humana e uma filosofia de orientação decorrente do materialismo dialético. [...] 0 pensamento marxista esclareceu para ele a revolta de 1917, vivida nas trincheiras e ligada à Revolução da URSS. [...] Era na prática um engajamento que justificava sua adesão ao Partido Comunista e sua militância na Internacional do Ensino ${ }^{3}$. E era, para seu pensamento, entrar sem cessar no centro

3- Freinet excursionou para a Rússia e teve contatos com a política da URSS. Sobre essa política e seu caráter modernizador, observamos a documentação presente em Lenine (1981). das contradições de qualquer sistema [...]. (FREINET, 1979, p. 120)

Embora fiel ao pensamento marxista, antecedentes históricos de Freinet revelam também o seu desligamento do antigo PCF Partido Comunista Francês, que atribuímos à discordância ao dogmatismo partidário, posteriormente verificável em um dos princípios na Carta da Escola Moderna. Junto com a defesa do cooperativismo e autogestão, a carta revela a heterodoxia no pensamento e ação do pedagogo.

Esse caráter heterodoxo acerca do cooperativismo e da autogestão na análise freinetiana, não obstante o seu caráter popular, em tese, repousa na consciência de Freinet quanto à discussão crítica entre Marx e Proudhon, considerado "pai do cooperativismo" 4 . Nessa discussão, o autor preservou e desenvolveu as noções de cooperativismo e autogestão. Ao mesmo tempo, reuniu contribuições da autonomia e livre expressão provenientes de ideais revolucionários iluministas, particularmente a partir de Rousseau ${ }^{5}$. Nesse processo articulado de análise e reflexão a respeito dos fundamentos da pedagogia freinetiana, observamos o caráter crítico e heterodoxo em sua teoria e metodologia.

Nesse panorama geral acerca da obra freinetiana, procuramos demonstrar a sua relevância e atualidade no presente contexto histórico, a partir do qual nos propomos a estudar e analisar esses referidos aspectos.

No presente contexto da educação pública, desde fins do século XX, procuramos justificar o tema também a partir da influência condicionante de políticas e critérios tecnocráticos, mercadológicos e financeiros ${ }^{6}$ sobre o grau de autonomia da pedagogia moderna. Observamos, em contrapartida, a relevância crítica e a atualidade da obra

4- Para o acratismo e o cooperativismo mutualista de Proudhon, referenciamo-nos em seu Sistemas das contradições econômicas ou filosofia da miséria. São Paulo: Escala, 2007.

5- Vide Carlota Boto (1996) e Freire (1996).

6 - Análise crítica presente em Warmling; Astier (1997) sobre pseudoreformas de ensino na França, sem mudanças estruturais. 
pedagógica de Freinet, devido à contribuição original relacionada à plena autonomia, ao livre cooperativismo e à autogestão escolar, desenvolvidos estruturalmente em seu projeto político-pedagógico da chamada escola moderna.

Nessa perspectiva geral, observamos, por decorrência, a sua dimensão maior como uma pedagogia solidária internacional, dirigida ao desenvolvimento do educando pelo trabalho, principalmente a partir de condições técnicas objetivas, mas também de condições organizativas de administração e gestão democráticas diretas ou reais, para uma escola verdadeiramente risonha e franca, expressão comumente atribuída ao autor.

\section{Freinet: a autonomia frente às adversidades}

Conforme a literatura existente, a construção da pedagogia do trabalho ou da escola moderna, do francês Célestin Freinet (Gars,1896, Vence,1966), não foi elaborada $a$ priori e academicamente. Pelo contrário, teve influência de sua experiência de vida desde os primórdios, quando foi pastor de ovelhas, nos Alpes Marítimos, já nos seus primeiros anos de vida (FREINET, 1979). Essa profissão lhe exigia tomar decisões importantes relacionadas à segurança do rebanho, principal fonte de sustento de sua família humilde.

Pensamos que essa experiência profissional influenciou a concepção e o desenvolvimento de sua obra pedagógica, levando-o a valorizar a autonomia e a livre descoberta, que ulteriormente se tornariam base para a consideração da importância da livre expressão e da livre pesquisa. Esses seriam valores importantes também para educandos superarem o difícil isolamento rural e provinciano a que estavam submetidos.

A experiência histórica adversa na biografia de Freinet também deve ser considerada, visto que aos dezoito anos iniciou sua experiência traumática como soldado nas batalhas da I Guerra Mundial (1914), mesmo ano em que iria iniciar o magistério em Nice. Após um ano de combates, seus pulmões foram seriamente lesionados por gases tóxicos em Verdun, com sequelas irreversíveis à respiração. Freinet buscou terapia médica ao longo de quatro anos (SAMPAIO, 1989; ELIAS, 1997; LEGRAND, 2011), mas a ineficácia dos tratamentos o fez assumir essa realidade e conformar-se com a deficiência.

Embora fatigado e extenuado fisicamente, era lhe exigido ser objetivo e comunicar verbalmente o essencial (PENTEADO, 1979), algo, a seu ver, necessário à pedagogia moderna baseada na experiência e em contraposição direta à escolástica, então baseada no verbalismo intelectual e abstrato, em geral estranho às necessidades dos educandos e às famílias de aldeões.

Em 1920, iniciou sua atuação como educador em Bar-sur-Loup e nessa nova etapa começou a pesquisa e a discussão de uma nova pedagogia assumidamente popular, baseada no trabalho, influenciada pelas experiências-limite que viveu. Nessa fase, conheceu primeiro a obra de Rousseau a respeito do reconhecimento da natureza peculiar infantil. Podemos dizer que vem daí sua ponderação acerca da defesa da autonomia e da livre expressão presentes como ideais na Revolução Francesa e na Declaração Universal dos Direitos do Homem e do Cidadão, embora considerasse uma referência em geral distorcida das elites ${ }^{7}$.

Por outro lado, observamos seu viés multifacetado que, ao lado do fundamento baseado na razão, tem a influência de Teilhard de Chardin quanto à aproximação científica entre razão e espiritualidade humanista, em termos antropológicos, segundo o qual "nada é tão delicado e fugidio, por natureza, quanto um começo" (apud FREINET, 1979). Nesse sentido, eis a valorização por Freinet do papel da livre pesquisa e da livre expressão como meios essenciais para a "ascensão da vida".

Essa pesquisa adquiriu articulações mais importantes devido ao novo e moderno órgão

\footnotetext{
7- "[...] E é tradição referir-se a Rabelais, Montaigne e J.-J.Rousseau [...] (mas) tais idéias que os intelectuais julgam ter descoberto não correm desde sempre entre o povo [...] não foi o erro escolástico que [...] deformou a essência, para monopolizá-la [...]?" (FREINET, 1979, p.3)
} 
Nouvelle Éducation, bem como o Congresso Internacional de Educação Nova, em 1932, na cidade de Nice. Freinet teve contato com os conceitos e materiais fundamentais de Maria Montessori, com a Casa dei Bambini, os centros de interesse de Decroly, as reservas infantis e o interesse em Claparède, o texto livre de Bovet, a escola ativa de A. Ferrière (1946). Posteriormente, Freinet também tomou conhecimento do escotismo de Baden-Powell, baseado no ensino ao ar livre, bem como da escola-canteiro ou escola-laboratório de John Dewey, revisando-as crítica e dialeticamente, no campo pedagógico-moderno.

Paralelamente, Freinet, nessa fase, demonstrou cidadania ativa em sua aldeia, na qual liderou um movimento e fundou uma primeira cooperativa, em Bar-su-Loup, em defesa da instalação da energia elétrica (LEGRAND, 2011). Iniciou também sua militância sindical e partidária comunista (LEGRAND, 2011), inclusive excursionando à antiga URSS (União das Repúblicas Socialistas Soviéticas). Foi nesse período que tomou contato com os debates liderados por Lênin no campo da educação operária ${ }^{8}$.

Freinet retornou mais bem preparado e já em 1928, em Saint-Paul de Vence, fundou a Cooperativa de Ensino Laico, com os principais meios de produção de sua pedagogia, como o uso da imprensa de tipos móveis e a correspondência interescolar de alcance internacional. Mas, a oposição conservadora local mais interessada na rentabilidade turística forjou uma falsa acusação com intenções políticas (LEGRAND, 2011), que, mesmo sem provas, conduziu a câmara arbitrariamente a exonerá-lo do sistema municipal.

Como resistência a esse jogo político dominante, Freinet fundou o Movimento de Educação Cooperativa nos anos 1930, que obteve sucesso de publicações de material didático, permitindo reunir recursos e conquistar autonomia financeira.

8 - Para consulta mais consequente aos planos educacionais da antiga URSS, vide Lenine (1981).
Assim, em 1934, migrou para Vence (LEGRAND, 2011), cidade na qual fundou a própria escola cooperativa experimental e autogerenciada, para atendimento de filhos de famílias operárias e do serviço assistencial de Paris, consolidando, assim, sua obra. Mas, em 1939, eclodiram os conflitos da II Guerra Mundial. 0 estado de saúde do pedagogo se deteriorou (SAMPAIO, 1989), sendo preso e encaminhado ao campo de concentração de Var. Detento, mas, resistente à condição, alfabetizou outros presos. Foi retirado por Elise Freinet e encaminhado ao hospital do campo de concentração, sendo libertado apenas em 1941 (SAMPAIO, 1989).

Como libertário engajado, tomou a decisão de atuar como guerrilheiro maquisard, nas Forces Françaises de l'Intérieur (FFI), na Resistência Francesa ${ }^{9}$. Como tal, tornou-se líder na comuna e zona do Briançonnais.

Três anos após o fim guerra, já em 1948, a Cooperativa de Educação Laica foi rebatizada como ICEM - Institut Coopératif de l'École Moderne (LEGRAND, 2011) - agora em Cannes, baseada no cooperativismo para a fabricação de material didático e pedagógico acessível (PENTEADO, 1979). 0 número de participantes entre pais e docentes chegou a vinte mil (PENTEAD0, 1979; SAMPAIO, 1989).

Mas, em 1950, Freinet foi expulso do PCF, por discordâncias burocráticas e ideológicas (LEGRAND, 2011). Em 1956, participou da campanha nacional da crítica à superlotação de classes e à reivindicação da defesa de turmas discentes de no máximo vinte e cinco alunos para uma melhor interação didática e qualidade do ensino público.

Em 1966, Freinet faleceu em Vence. A pedagoga e artista Elise, sua atuante colaboradora e companheira, manteve a continuidade de sua obra, da qual destacou a livre expressão como essência da pedagogia da Escola Moderna.

9- Sobre Freinet maquisard consideramos a introdução de Elise Freinet (1969). 
Retrospectivamente na análise, notamos o engajamento e o enfrentamento das adversidades por Freinet, traço importante para a compreensão de sua personalidade e história. Essa experiência viva revela a construção e a valorização de sua autonomia e independência, resultante da necessidade de decidir e enfrentar permanentemente realidades adversas por meio do trabalho. A nosso ver, esse aspecto influenciará a sua obra, pensamento e ação. Portanto, a autonomia em sua vida não constitui uma ideia surgida $a$ priori, mas um valor resultante de uma série de experiências de vida e de dificuldades superadas por meio do trabalho, pesquisa e engajamento popular. Tais aspectos tornam-se centrais na construção da pedagogia Freinet, cujo desenvolvimento lógico e coerente conduziu sua obra ao estabelecimento do cooperativismo e autogestão escolar, como condição para a plena autonomia da escola moderna.

\section{A autonomia radical, o livre trabalho e a livre organização para a liberdade pedagógica moderna}

$\mathrm{Na}$ análise desse histórico de Freinet, bem como de suas influências pedagógicas, observamos alguns aspectos que se constituirão as colunas centrais de seu pensamento e ação: a autonomia como razão última e o trabalho como atitude vital diante de adversidades; a defesa da livre expressão, como consequência necessária da autonomia, e a livre pesquisa, como consequência do trabalho como meio gerador de conhecimento novo e, finalmente, a cooperação e autogestão como resultado coerente e lógico dessa experiência teórico-metodológica.

Consideramos na análise freinetiana a autonomia e a livre expressão como elementos indissociáveis, razão pela qual enunciamolas resumidamente como a autonomia, assim como o livre trabalho e livre pesquisa apenas como o trabalho e, finalmente, a cooperação e autogestão como organização. Desse modo, resumimos a autonomia radical, o livre trabalho e a livre organização, categorias centrais no pensamento e análise freinetianos.

Antes de alcançar esse desenvolvimento teórico-metodológico, em seus primeiros anos Freinet analisou criticamente os fundamentos e a prática da pedagogia escolástica, revendo sua própria experiência na escola dominante à época, a qual considerava traumática e domesticadora em função da separação, de caráter intelectualista e dogmática, entre conteúdo e forma didáticas de um lado e, de outro, das necessidades reais de educandos. Assim, tornou-se crítico acerbo e pesquisador pedagógico para a construção de uma pedagogia efetivamente científica. Observava que a pedagogia escolástica no aspecto geral apenas sujeitava educandos à passividade, à repetição e à subordinação, em frontal contradição quanto à autonomia do educando, fundamental para o rigor da vida no campo e para a vida. Em Para uma escola do povo, Freinet (1998, p. 19) considerou que:

Esta escola já não prepara para a vida; não está voltada nem para o futuro, nem mesmo para o presente; obstina-se num passado que não volta [...]. [...] A Escola que não prepara para a vida, já não serve a vida; e é essa a sua definitiva e radical condenação [...].

Para a fundamentação desse novo trabalho pedagógico, Freinet defendeu o conceito psicológico de trabalho-jogo cujo fundamento está no objetivo concreto do labor, da construção do conhecimento sensível, do trabalho como meio lúdico em si mesmo, baseado na necessidade natural na psicologia do educando. Tal conceito opunha-se ao dominante jogo-trabalho, o ersatz, que simula a atividade laboral sem necessariamente realizála ou atingir um objetivo concreto.

Em Ensaio de psicologia sensivel II, o autor assim se refere ao conceito de ersatz - a lógica substitutiva ou simulada de vida, contrária ao trabalho real - relacionada à escola tradicional dominante: 
0 que é mais grave ainda é que essas soluções ersatz não estão na ordem natural das coisas; elas não passam de uma atitude excepcional e irregular em face de uma impotência também acidental e irregular. (FREINET, 1976, p.11)

Mas Freinet dialeticamente não descartava a função do ersatz (substitutivo) como um todo. Compreendia que o trabalho enquanto jogo em si, necessário ao educando, poderia, em determinadas circunstâncias impeditivas do real do trabalho-jogo, ser benéfico se em seguida permitisse a realização do trabalho-jogo e respectiva sublimação.

Diante desse quadro geral, Freinet estabeleceu uma de suas leis psicopedagógicas (vigésima-quarta), segundo a qual o trabalho constitui corretor de regras ou lógicas de vida ersatz. Sob a teoria do tateamento experimental, como assim denominou, Freinet desenvolveu técnicas didáticas para trabalho livre $\mathrm{e}$ cooperado, com fins libertadores principalmente quanto à expressão, sem, contudo, confınar educandos em salas de aula.

Esse problema em particular Freinet (1969) descreveu em a Pedagogia do bom senso ou Les dits de Mathieu, classificando-o criticamente como parte de uma "pedagogia de casaca". Para ele, tratava-se de uma das primeiras contradições da escolástica. Assemelhou esse confinamento a um campo de concentração e de condicionamento quase animal, motivo pelo qual procurou retirar os educandos desses locais, levando-os para fora dos muros escolares, em livre direção aos limites da aldeia e do campo.

Analogamente à antiga peripatética, mas livre do caráter tecnicista dos antigos liceus, o educador elaborou o procedimento didático da aula-passeio, para anular o isolamento de educandos em salas de aula e, principalmente, estimular a observação sensível e a descoberta da realidade e da natureza, bem como das atividades produtivas (SAMPAIO, 1989) existentes na aldeia em torno da escola e dos Alpes Marítimos. Procurava, nessa técnica, também a aproximação mútua entre escola e comunidade por meio de rudimentos da pesquisa de campo, o estudo do meio, coerente à noção do educando como sujeito ativo nesse processo didático. Freinet (1969) considerou essa nova e moderna noção de espaço escolar aberto à comunidade como uma reserva infantil em oposição à edificação fechada e sem comunicação com o mundo exterior.

A experiência da aula-passeio, semelhante à de uma pequena expedição, era uma das principais atividades discentes, cujas indagações, opiniões e impressões do educando eram expressas e discutidas em livres textos e registradas em um diário escolar (livro de vida), que constituía uma das principais ferramentas de livre expressão e reflexão autônoma da criança. A produção de livre escrita e de pesquisa discente e docente acabavam por constituir complementarmente o próprio material didático. Por essa razão e para a coerência ao princípio pedagógico moderno, Freinet defendeu a abolição de manuais escolares (FREINET, 1979), ferramenta central da separação escolástica entre vida e realidade.

Com a construção pedagógica da autonomia por meio do livre trabalho, da livre expressão, da livre pesquisa, o espaço escolar decorrente do modelo escolástico necessitava ser abolido e reorganizado a partir da lógica e dinâmica do trabalho livre, coletivo, criador, sob livre cooperação.

Para defender o caráter científico dessa pedagogia crítica, Freinet a explanou como uma teoria objetivamente formulada e baseada em um empirismo experimental a partir do trabalho de descoberta ou tateio experimental do educando, cujos fundamentos conceituais se assentam diretamente na construção da autonomia por meio do trabalho (FREINET, 1979). Esse processo constitui, para Freinet (1977), um método natural consoante às necessidades, intuições, interesses, impulsos e motivações do educando.

Elise Freinet (1979), na obra O Itinerário de Célestin Freinet, considerou principalmente 
a livre expressão como elemento distintivo e crítico em seu método natural, em contraposição a outros métodos e teorias psicopedagógicas orgânicas ao escolasticismo.

Nesta etapa de análise, podemos considerar alguns aspectos fundamentais presentes na formulação teórico-crítica e praxiológica de Freinet. Reiteramos a influência da experiência concreta do trabalho presente na biografia de Freinet, cujo resultado foi a valorização da autonomia, mas também o compromisso com a razão sensível e humana, presente em Rousseau, sobretudo crítica quanto às origens da desigualdade. Nesse aspecto, Freinet estava consciente de sua origem trabalhadora, camponesa. Sua sensibilidade se voltava à consciência da desigualdade e às condições de vida e produção dessa população.

Nesse contexto, observamos uma influência marxista que se manifesta implicitamente em três aspectos: 1) na presença da teoria da alienação do sujeito, na forma de crítica e prevenção pedagógica; 2) na teoria das relações materiais de produção, quanto às condições objetivas geradas pelas técnicas de vida; e 3) na doutrina internacionalista marxista, presente nos correios interescolares.

No primeiro aspecto, observamos a crítica marxista à alienação ${ }^{10}$ nos métodos e nas consequências negativas dos dogmas pedagógicos do escolasticismo, no qual o objetivo pedagógico da autonomia da criança não era visado, mas sim a sua passividade. Essencialmente, para Freinet, o escolasticismo era baseado na separação da escola da realidade de vida da criança e da sua família e em repetições e memorizações.

A segunda evidência marxista em Freinet reside na consciência quanto às condições objetivas da relação infraestruturasuperestrutura ou às relações materiais de produção ${ }^{11}$. 0 pedagogo originalmente

10- Referimo-nos particularmente à análise de Marx sobre a mercadoria e a divisão de trabalho e manufatura. Confira Marx (1988, p. 45-78 e p. 254-276)

11- Marx (1988). Acrescentamos nesta passagem, o texto A ideologia alemã Feuerbach. Oposição das concepções materialista e idealista (MARX, 1982). introduz técnicas de trabalho (técnicas de vida), organizadas quase tacitamente como um sistema para apropriação e uso coletivo entre educandos e educadores e pais, a partir da prensa gráfica de tipos móveis para a impressão de livres textos e livres desenhos ${ }^{12}$, trabalho que permitiu também a elaboração de suportes comunicativos (jornal, cartazes, folhetos etc.), a partir da técnica complementar do silk screen.

Freinet (1969), em Por uma escola do povo, também promoveu e registrou mudanças estruturais da classe escolar: aboliu estrados e plantas mecanicistas do interior arquitetônico da tradição escolástica, cujo espaço servia funcionalmente à centralização da autoridade docente e não à noção da criança como sujeito ativo do processo de ensino-aprendizagem. Além disso, criou o conceito de cantos pedagógicos, que tornou a sala de aula semelhante a um ateliê de trabalho e criação multidisciplinar.

Para auxílio à metodologia da livre pesquisa, Freinet (1969) orientou didaticamente as crianças a uma espécie de pré-iniciação científica, a partir de seus interesses e necessidades, com técnicas de documentação sistemática por fichas e consulta em fichários. Coerentemente, estabeleceu um processo de livre autoavaliação coletiva baseada em indicadores de produção para livre uso, inspirada em etapas gerais de desenvolvimento.

0 terceiro aspecto marxista em Freinet refere-se ao caráter assumidamente internacionalista de seu sistema. Reunindo a condição objetiva da técnica e a sua respectiva apropriação coletiva, o autor, em referência à crítica ao isolamento rural e provinciano, promoveu o uso e desenvolvimento de correios interescolares. Com isso, Freinet se aproximava da noção iluminista de cidadão do mundo, mas sobretudo da doutrina internacional de Marx. Ao mesmo tempo, como cientista da educação, buscava também submeter processos e resultados sistematicamente à avaliação e conferência científicas de colaboradores e pesquisadores

12- Análise teórica e metodológica do papel do desenho e o estudo psicopedagógico desenvolvido por Fa a partir de Freinet (1977). 
internacionais, perfazendo uma comunidade de caráter aberto, solidário e internacionalista, com vistas a uma nova sociedade.

Nesse aspecto, Freinet no décimo princípio da Carta da Escola Moderna, considerava que a pedagogia é inerentemente internacional: “[...] para nós, mais do que uma profissão de fé, mas uma necessidade para o trabalho". (BEAUNIS, 2009)

Observamos, porém, que Freinet desenvolve uma análise e interpretação heterodoxa de Marx, razão pela qual o consideramos marxiano e menos marxista no sentido dogmático do termo. Retrospectivamente, observamos como sintomática a sua expulsão partidária, sofrida por divergências, e a busca pela coerência radical para a libertação do homem pela própria perspectiva marxista.

Essa heterodoxia possivelmente se relaciona à organização geral baseada no cooperativismo $^{13}$ e na autogestão para a produção social da escola moderna ou pedagogia do trabalho.

Dialeticamente, Freinet se aproxima nesse aspecto da querela entre Marx e Proudhon ${ }^{14}$ e reafirma a importância da autonomia em sua análise. Freinet, nessa perspectiva geral, também contribuiu para uma original análise e interpretação do marxismo e se aproximou de autores como Gramsci, Benjamin e outros.

Nessa análise geral acerca dos fundamentos da escola moderna, a partir da autonomia radical, mas principalmente do livre trabalho e suas técnicas, da livre organização como condições reais para a liberdade pedagógica moderna, observamos um caráter original e peculiar na obra de Freinet: a sua ampla dimensão solidária ${ }^{15}$, cujo autor observava como fenômeno inerente as "solidariedades fundamentais de todas as formas de Vida"

13 - Marx (1988) em uma primeira análise considerou que "A cooperação permanece a forma básica do modo de produção capitalista, embora sua figura simples mesma apareça como forma particular ao lado de suas formas mais desenvolvidas".

14 - Referimo-nos à crítica da Miséria da Filosofia de Marx, resposta à Filosofia da Miséria de Proudhon. Marx, em carta, realizou esclarecimentos críticos em Sobre Proudhon. (MARX; ENGELS, 1983, p. 20-28, vide nota 4). 15- Referenciamo-nos nos fundamentos gerais da solidariedade, em Singer (2002). Em pedagogia, referenciamo-nos em Gadotti (2009).
(FREINET, 1979) em contraposição às relações competitivas e meritocráticas. Freinet não restringiu a solidariedade às relações didáticas entre educador-educandos, mas avançou também às relações docentes, consolidando a sua obra estrutural e efetivamente como um projeto politico-pedagógico maior.

\section{Livres relações autônomas: uma pedagogia solidária internacional}

Baseados na análise dos fundamentos da autonomia radical na pedagogia Freinet, entre os quais o da livre expressão e o do livre trabalho, bem como os fundamentais e decisivos meios concretos, como as técnicas de vida, consideramos por extensão três contribuições científicas decorrentes, originais e decisivas do pedagogo.

A primeira reside no esforço de coerência lógica quanto às relações didáticas críticas entre educador e educandos. Se essas são dirigidas à construção da real autonomia, consequentemente essa relação se estendeu mutuamente entre educadores. Nesse ponto, observamos a principal consequência humana, teórica, política e social da moderna pedagogia do trabalho freinetiano. A única relação social possível para essa pedagogia da autonomia radical, portanto, corresponde ao cooperativismo, para a produção social da livre relação de trabalho entre pares. Nesse mesmo raciocínio, a horizontalidade necessária para administração política-pedagógica da escola moderna, consequentemente, implicou a defesa e a construção da autogestão escolar ${ }^{16}$.

Mas Moacir Gadotti (2009, p. 32-33), em Educar para a cooperação, reflete o significado essencial desse sistema:

[...] na autogestão, a formação para a gestão não é um processo educativo restrito ao setor administrativo. A formação para a gestão em empreendimentos autogestioná-

16 - Para Brasil (2005, p. 10), "[...] subentende a existência de autonomia e [...] capacitação para administração coletiva [...] direito à informação e democracia nas decisões. [...] como partilha de poder e controle da vida do empreendimento coletivo. 
rios dirige-se ao conjunto das pessoas ligadas ao empreendimento, embora tenha que existir formação específica e professional para certos quadros institucionais de acordo com suas responsabilidades. Trata-se de uma formação para a gestão colaborativa e o trabalho de equipe. [...] Ela não se restringe a aspectos informativos e formativos, mas envolve também aspectos organizativos e produtivos. Com a autogestão, todos participam das decisões independentemente da função que executam.

Para Elias (1997, p. 65):

Freinet jamais aceitou a competição (grifo nosso) individual que existia nas escolas; em seu lugar propôs a vida cooperativa, idéia reforçada no encontro com Cousinet e Profit, em Montreaux (1924). 0 primeiro preconiza o trabalho em pequenos grupos e Profit propõe a solidariedade pela cooperativa escolar. Freinet vai mais longe: sua pedagogia circula entre o individual e o coletivo, procurando desenvolver ao máximo o senso cooperativo.

Nesse aspecto, Freinet manteve a coerência ética estrutural nessas relações discentes e docentes na Cooperativa de Ensino Laico e no Instituto Cooperativo de Escola Moderna, documentados no órgão L'Educateur (FREINET, 1985). Enfatiza-se, portanto, que essa perspectiva ética radical não se restringiu à cooperação e à autogestão administrativas apenas entre educadores, mas, principalmente, para os educandos. Freinet (1969, p. 149), em Para uma escola do povo, alertou que para a constituição de uma real cooperativa escolar:

[...] não se trata de fundar, como por vezes acontece, um agrupamento formal no papel, com o objectivo de comprar um material qualquer mediante o pagamento de uma cotização mensal, mas de uma verdadeira sociedade de crianças (grifo nosso) capaz de administrar a quase totalidade da vida escolar.

Nesse aspecto, Paul Singer (2009, p. 12), no Prólogo de a Economia solidária como praxis pedagógica, de Moacir Gadotti (2009), afirma:

Convém recordar que um dos princípios basilares do cooperativismo [...] é que, a qualquer momento, novos trabalhadores tenham o direito de se associar a empreendimentos solidários e que associados a tais empreendimentos tenham o direito de deixá-los [...]. A autogestão só é válida enquanto os trabalhadores participarem dela por sua própria vontade. Se a participação em empreendimentos solidários se tornasse obrigatória pela eliminação de todos os outros modos de produção de determinado país, os trabalhadores não seriam mais os donos do seu destino, que ficaria sujeito à vontade dos que teriam poder para autorizar e impedir o funcionamento dos diversos modos de produção.

Ao mesmo tempo, como visto anteriormente, Freinet não operava didática e pedagogicamente a partir de ideias puras, mas, consciente das relações materiais concretas de produção, sistematizou o uso e a apropriação coletiva das técnicas em torno da imprensa escolar e de outras novas mídias daquele contexto. Essa medida, além de oferecer as condições objetivas concretas para a produção dessas relações didáticas, gerava principalmente as condições reais de autonomia, livre trabalho e livre expressão de educandos e também de educadores.

A pedagogia de Freinet, nesse aspecto, proporcionou a organização da escola popular como um centro de comunicação por excelência, mas baseado no trabalho cooperado real. Nesse aspecto, opunha-se à escola nova cujas considerações gerais já eram existentes mais amplamente na teoria liberal da escolacanteiro ou escola-laboratório, de John Dewey (1971). Mas, conforme interpretação de Élise 
Freinet (1979, p. 88), em O Itinerário de Célestin Freinet, a seu ver John Dewey embora representasse o mais prolífico pensador do movimento da Escola Nova, por outro lado desenvolveu pedagogicamente:

[...] uma teoria aparentemente perfeita no plano das idéias, (mas) na realidade é isolada da prática, deixada ao acaso do improviso, quando é na prática que se pode encontrar solução para os problemas da vida cotidiana. [...] Lamentamos que Dewey não tenha feito delas nenhuma prática escolar a ser promovida: a organização técnica da escola a que propõe depende de doutrinas filosóficas, que ele justificará em sua concepção de uma escola-laboratório ideal, que nunca se realizará. Será simplesmente pela crítica autorizada que ele entrará na prática pedagógica, pela análise de escolas novas americanas, criadas à sua revelia. A concepção de Dewey, baseada no princípio da continuidade (da criança na escola, da escola na sociedade, do homem na natureza), é mitológica, estranha à experiência vivida, e subestima o meio social constructor ou destruidor da personalidade da criança, segundo a classe social a que pertença.

Em contraposição à escola nova, a escola moderna de Freinet se baseou distintamente no efetivo trabalho livre e cooperado, a partir de técnicas concretas e da relação de ensino e aprendizagem aberta no vilarejo em torno da escola. Mais do que o raio geográfico montanhoso e provinciano da escola, Freinet agiu radicalmente para tornála uma internacional, por meio da técnica de correios interescolares.

Assim, tal cooperação internacional entre educandos, educadores e pedagogos freinetianos, proporcionou a realização de conferências, boletins, avaliações, discussões e intercâmbios, demonstrando concreta e plena coerência teórica, metodológica e praxiológica de Freinet, no sentido de uma construção permanente e dinâmica de cultura de pesquisa fundamental baseada na livre expressão e na geração do conhecimento novo a partir da cooperação internacional.

Freinet ainda observou e denunciou o caráter de classe presente no ensino público, razão pela qual seu compromisso ético, social e político voltou-se aos educandos de famílias carentes e aquelas abandonadas em serviços assistenciais, mais coerente à sua própria origem camponesa. Freinet (1998, p. 79) denunciou, em A educação pelo trabalho:

As práticas pedagógicas de educação nova tornam ainda mais evidente as alienações da escola do povo no regime capitalista. Deterioração, obsolescência dos locais, falta de instrumental educativo e de créditos, hostilidade dos poderes públicos a toda iniciativa dos professores. Estado de privação e de subalimentação da infância proletária. Falta de formação dos professores primários, relegados ao empirismo pedagógico, diante dos professores universitários altamente especializados, possuidores de todos os meios que favoreçam suas obras pedagógicas. Oposição permanente entre uns, de cultura intelectualista, e outros de cultura popular de sensibilidade e bom gosto. Existe uma escola de Classe.

Não se trata, portanto, de uma opção pelo sistema privado. Pelo contrário, o autor buscava radicalizar a defesa do ensino público, mas em termos populares. Nesse aspecto, para Dallari (1998), não se distingue o objetivo entre os sistemas estatal e privado, mas essencialmente o desenvolvimento pleno e integral do educando em sociedade. Freinet, nessa esfera pública, buscou radicalizar a independência da escola popular em nova articulação, de um regime cooperado e autogestionário com a comunidade, liberto de injunções extrapedagógicas: 
Servir à verdade, ao direito, à justiça, não se usa mais uma sociedade que pisoteia essas noções. Temos de servir a um regime: pobres entre pobres e educando filhos de pobres, deveríamos colocar a nossa ascendência moral, nosso devotamento, nosso saber a serviço dos ricos exploradores: mutilados, odiando a guerra que fizemos, teriamos que mentir sem parar a nossos alunos, inculcar-lhes uma moral essencialmente contestável, que não tem relação alguma com a verdadeira moral que praticamos e ensinamos. 0 que se gostaria, nós o sabemos e vemos muito bem, seria que continuássemos a utilizar o sistema imoral e antipedagógico que prepara, não homens mas servidores dóceis de um regime; gostariam de obrigar-nos, a nós, educadores proletários, a servir sem reservas à escola da classe burguesa. A isso dizemos não. Somos educadores. Nosso primeiro dever é respeitar as crianças que nos são confiadas, educá-las, prepará-las. Para isso, opomo-nos a todo dogmatismo que se justifica por considerações extrapedagógicas. Não estamos a serviço de governos que passam, nem de regimes que mudam; estamos a serviço das crianças, a serviço da sociedade para a qual queremos prepará-las, segundo as técnicas da verdade e da liberdade, felizes e orgulhosos de apoiar-nos, para isso, em todas as forças que buscam o mesmo objetivo de libertação e renovação. (FREINET, 1998, p.82)

Trata-se então, a nosso ver, da pedagogia do trabalho ou escola moderna, de uma perspectiva de autonomia radical e estruturalmente enraizada desde a sua concepção, a sua estrutrutura e o seu funcionamento para fins de "libertação e renovação”. Isso, na visão de Freinet, corresponde a um regime cooperativo, autogerido e em comunicação internacional que, devido ao seu caráter embrionário na história, somente no presente contexto ganha dimensão maior, mas ainda pouco considerada na pedagogia de Freinet: a de uma pedagogia solidária internacional.

A relevância e atualidade da pedagogia Freinet no presente contexto histórico adquire consistência diante da hegemonia de políticas educacionais baseadas em critérios tecnocráticosconcorrenciais, mercadológicos e financeiros, que interferem no grau de liberdade pedagógica moderna e mais amplamente na noção da educação como direito humano essencial.

\section{Considerações finais}

Baseados em uma revisão geral, procuramos sustentar a hipótese do caráter solidário da pedagogia freinetiana a partir da verifıcação de seus fundamentos como a autonomia, a livre expressão, o livre trabalho cooperado, a livre pesquisa, a avaliação autônoma e o correio interescolar.

0 aprofundamento desse caráter ético da solidariedade não se restringe às relações didáticas entre educandor e educando, mas se encontra também na relação docente entre educador e educador.

Nesse aspecto, como condição objetiva para a execução do projeto político-pedagógico solidário da escola moderna, bem como uma perspectiva política de autonomia radical pedagógica, Freinet baseou o seu trabalho no cooperativismo internacional e na autogestão escolar.

A partir dessa perspectiva, torna-se possível refletir a respeito da superação da polaridade estatal-privado, para efetivamente construir uma esfera pública-democrática, popular. Nesse sentido, a pedagogia freinetiana se inscreve centralmente no campo das discussões acerca da economia e cultura baseadas no trabalho solidário.

Com a presente consideração, procuramos demonstrar a relevância e a atualidade científicas dessa pedagogia moderna e crítica que, em si, pressupõe novos estudos e pesquisas para a superação do presente status quo, com a construção da escola do trabalho cooperado e popular, qualificada por Freinet como moderna e do futuro, mas, também, risonha e franca. 


\section{Referências}

BEAUNIS, Claude. La charte de l'école moderne. In: ICEM. Disponível em: <http://www.icem-pedagogie-freinet.org/la-charte-deI-ecole-moderne>. Acesso em: 18 jun. 2011.

BOTO, Carlota. A escola do homem novo: entre o iluminismo e a Revolução Francesa. São Paulo: Editora da UNESP, 1996.

BRASIL. MTE. SPPE. ANTEAG. Autogestão e economia solidária: uma nova metodologia, v. 2. Brasilia, DF: MTE, 2005.

DALLARI, Dalmo de A. Direitos humanos e cidadania. São Paulo: Moderna, 1998.

DEWEY, John. Experiência e educação. São Paulo: Companhia Editora Nacional, 1971.

ELIAS, M. Del Cioppo. Célestin Freinet. 6. ed. Petrópolis: Vozes, 1997.

(Org.). Pedagogia Freinet: teoria e prática. Campinas: Papirus, 1996.

FREINET, Élise. 0 itinerário de Célestin Freinet: a livre expressão na pedagogia de Freinet. Rio de Janeiro: Francisco Alves, 1979.

FREINET, Célestin. A educação pelo trabalho. São Paulo: Martins Fontes, 1998. Publicada originalmente em 1947.

. Pedagogia do bom senso. São Paulo: Martins Fontes, 1985.

. 0 método natural II: a aprendizagem do desenho. Lisboa: Estampa, 1977.

. Ensaio de psicologia sensivel I: aquisição de técnicas construtivas de vida. Lisboa: Presença, 1976.

. Ensaio de psicologia sensível II: reeducação das técnicas de vida ersatz. Lisboa: Presença, 1976.

Para uma escola do povo: guia prático para a organização material, técnica e pedagógica da escola popular. Lisboa:

Presença, 1969.

FREIRE, Paulo. Pedagogia do oprimido. 40. ed. Rio de Janeiro: Paz e Terra, 2005.

Pedagogia da autonomia. 41. ed. São Paulo: Paz e Terra, 1996.

Conscientização: teoria e prática da libertação; uma introdução ao pensamento de Paulo Freire. São Paulo: Moraes, 1980.

GADOTTI, Moacir. Educar para a cooperação. In: Economia solidária como práxis pedagógica. São Paulo: Editora L, 2009. p. 31-46.

ICEM. Institut Coopératif de l'École Moderne. Pédagogie Freinet. Disponível em: <http://www.icem-pedagogie-freinet.org/ presentation-association-icem>. Acesso em: 18 jun. 2011.

LEGRAND, Louis. Célestin Freinet (1896-1966). Disponível em: <http://www.ibe.unesco.org/fileadmin/user_upload/archive/ publications/ThinkersPdf/freinete.pdf>. Acesso em: 20 nov. 2011.

LENINE, Vladimir llitc. A instrução pública. Moscovo: Progresso, 1981.

MARX, Karl Heinrich; ENGELS, Friedrich. Obras escolhidas. Lisboa: Avante-Progresso, 1982. p.4-74. 
MARX, Karl Heinrich; ENGELS, Friedrich. Obras escolhidas. Lisboa: Avante-Progresso, 1983. p. 20-28.

MARX, Karl. 0 Capital: crítica da economia política. 0 processo de produção do capital. 3. ed. São Paulo: Nova Cultural, 1988.

PENTEADO, José de Arruda. Didática e prática de ensino: uma introdução crítica. São Paulo: McGraw-Hill, 1979.

SAMPAIO, Rosa Maria Whitaker. Freinet: evolução histórica e atualidades. São Paulo: Scipione, 1989.

SINGER, Paul. Fundamentos. Solidariedade X competição na economia. Autogestão e heterogestão. In: Introdução à economia solidária. 4. ed. São Paulo: Perseu Abramo, 2002. p. 7-23.

Prólogo. In: GADOTTI, Moacir. Economia solidária como praxis pedagógica. São Paulo: Editora L, 2009.

WARMLING; Andréa; ASTIER, Jean. Mudar a escola... amanhã? (1997). In: ELIAS, M. Del Cioppo. Pedagogia Freinet. Campinas: Papirus, 1996. p.132-133.

Recebido em: 09.10.2012

Aprovado em: 09.10.2013

Antonio Takao Kanamaru é professor doutor da Escola de Artes, Ciências e Humanidades da Universidade de São Paulo (USP). 